\title{
Mobile Measurements of Particulate Matter CONCENTRATIONS IN URBAN AREA
}

\author{
Adnan Masic, Boran Pikula \& Dzevad Bibic
}
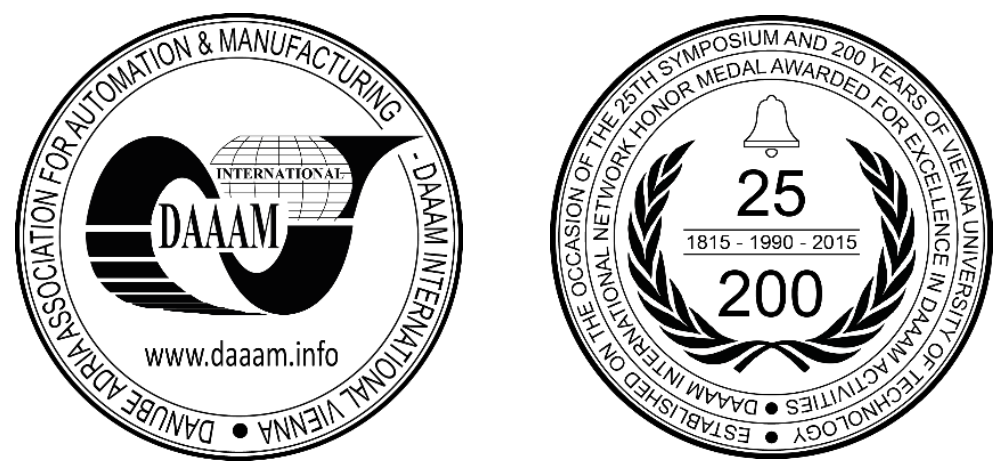

This Publication has to be referred as: Masic, A[dnan]; Pikula, B[oran] \& Bibic, D[zevad] (2017). Mobile Measurements of Particulate Matter Concentrations in Urban Area, Proceedings of the 28th DAAAM International Symposium, pp.0452-0456, B. Katalinic (Ed.), Published by DAAAM International, ISBN 978-3-902734-11-2, ISSN 1726-9679, Vienna, Austria

DOI: $10.2507 / 28$ th.daaam.proceedings.063

\begin{abstract}
The great attention is dedicated nowadays to the measurements of air pollutants' concentrations, and the air quality index (AQI), especially the particulate matter (PM) concentrations. However, measurements of PM concentrations are usually performed on fixed locations. Such data are very valuable, but not sufficient, because there is no information on spatial distribution of PM concentrations. For this purpose, a special low-cost device, based on laser diffraction method, for measurement of PM concentrations (PM1, PM2.5, PM10), has been developed and tested: both horizontal and vertical (using unmanned aerial vehicle) distributions are analysed over the urban area - city of Sarajevo.
\end{abstract}

Keywords: particle size analysis; laser diffraction methods; unmanned aerial vehicles; air quality index

\section{Introduction}

According to the World Health Organisation (WHO), the air pollution represents major environmental risk for human health [1]. Among all pollutants, the particulate matter suspended in the air (aerosol), have dominant effect on human health in Europe [2]. City of Sarajevo, Bosnia-Herzegovina, has characteristic and very strong air pollution during the winter, since it is located in the valley and affected by the natural phenomenon called temperature inversion [3]. Similar episodes can be observed in many other towns and cities with similar topology of terrain, for example Grenoble, France [4]. Therefore, monitoring of the PM concentrations in urban environment is essential. It is usually performed on fixed measuring locations operated by the Governmental institutions (if at all). Such measuring stations are very expensive, and their availability is limited. Data from such stations are very valuable, but there is no information about spatial distribution of air pollutants.

Another approach is presented here, as an alternative to the fixed monitors: development of the low-cost and highly mobile devices (air quality data loggers), which are suitable for recording of spatial distribution of PM concentration, both horizontally and vertically. These requirements (low-cost and high mobility) can be met using optical sensors, based on the laser diffraction method (instead of gravimetric analysis). Principal scheme of work of such optical sensors is presented in the Figure 1. 


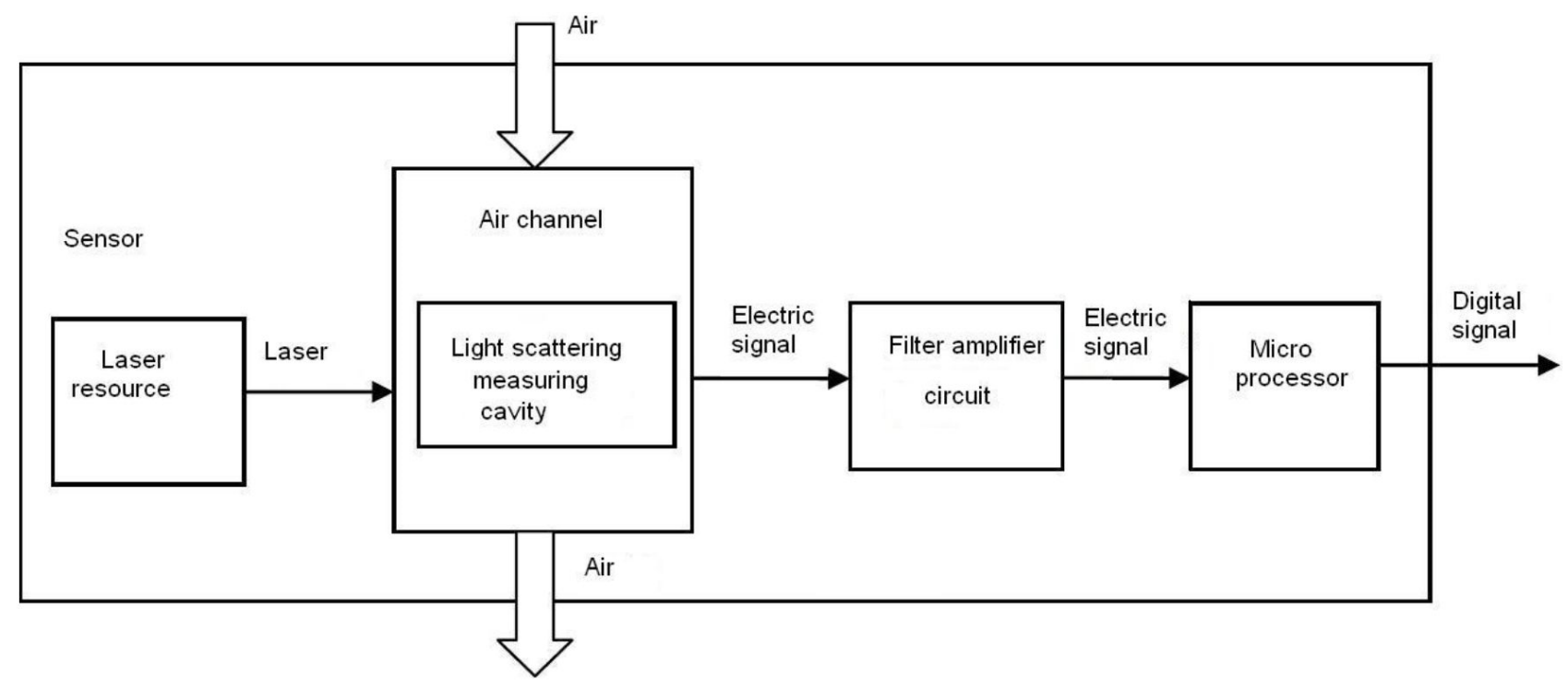

Fig. 1. Functional block diagram of the optical PM sensor

Laser light is scattered on the particulate matter in the air, producing certain effect on the photo-detector in the sensor. Electric signal from the photo-detector is amplified and processed internally using the Mie theory [5]. In short, the Mie theory is the solution of Maxwell's equations in the case of scattering of an electromagnetic plane wave by a homogeneous sphere.

The theory assumes that

1. all particles are spherical, optically homogenous and isotropic,

2. particles are illuminated by a plane wave of known wavelength,

3. the refractive index of both particle and medium (air) is known,

4. there is neither surface charge nor surface current on particles.

These assumptions should be carefully examined, since they can lead to significant uncertainty in the measuring process. Furthermore, the density of the particles must be assumed in order to calculate result in desired units $\left(\mu \mathrm{g} / \mathrm{m}^{3}\right)$. An excellent guide to the reliable measurements of PM using the optical sensors is the ISO standard 13320:2009 [6].

\section{The mobile particulate matter optical counter}

Primary instrument for this research is the mobile particulate matter optical counter (mPMOC in further test), which is based on our previous, in-house developed, data acquisition system, which was used to investigate vertical temperature profiles using unmanned aerial vehicles [7]. It was redesigned for this project and major modification was integration of the optical PM sensor. Special enclosure for the new data acquisition system was developed and optimized using computational fluid dynamics (CFD) simulations. The enclosures are manufactured using 3D printers.

The optical particulate sensor for the mPMOC was carefully chosen using the aforementioned criteria. It is the Plantower PMS5003 [8], with following specifications:

- Minimum distinguishable particle diameter: $0.3 \mu \mathrm{m}$

- Range of measurement: $0-1000 \mu \mathrm{g} / \mathrm{m}^{3}$

- Resolution: $1 \mu \mathrm{g} / \mathrm{m}^{3}$

- Maximum consistency error: $\pm 10 \%$

- Single response time: $<1 \mathrm{~s}$

- Standard volume: $0.1 \mathrm{dm}^{3}$

- Total response time: $<10 \mathrm{~s}$

- Working temperature range: $-10{ }^{\circ} \mathrm{C}-60^{\circ} \mathrm{C}$

- Working humidity range: $0-99 \%$

- Mean Time Before Failure: >3 years

Together with the PMS5003 sensor, mPMOC is equipped with: SHT31-D humidity and temperature sensor from ClosedCube, Measurement Specialties MS5611 barometer and u-blox NEO-M8N GNSS receiver. Communications with all sensors and logging of data was implemented by means of an Arduino Mega 2560 microcontroller. The SHT31-D and MS5611 sensors communicate with the microcontroller over the $\mathrm{I}^{2} \mathrm{C}$ bus, while the PMS5003 and NEO-M8N sensors use two serial ports (UART). 


\section{Results}

The mPMOC was designed in such a way that it can be easily adapted and installed on various mobile platforms (motorbike, bicycle, unmanned aerial vehicle etc.). First case, presented in the Figure 2, is the application of the mPMOC for use on the motorbike, so the city roads can be "scanned" for the PM10 air pollution. The city of Sarajevo has characteristic main longitudinal road of about $10 \mathrm{~km}$. The map background in the Figure 2 is Google Terrain Map, the track is shown using GNSS coordinates from mPMOC, and the color of the track line corresponds to the PM10 concentration. The image is generated by means of GpsVisualizer tool [9].

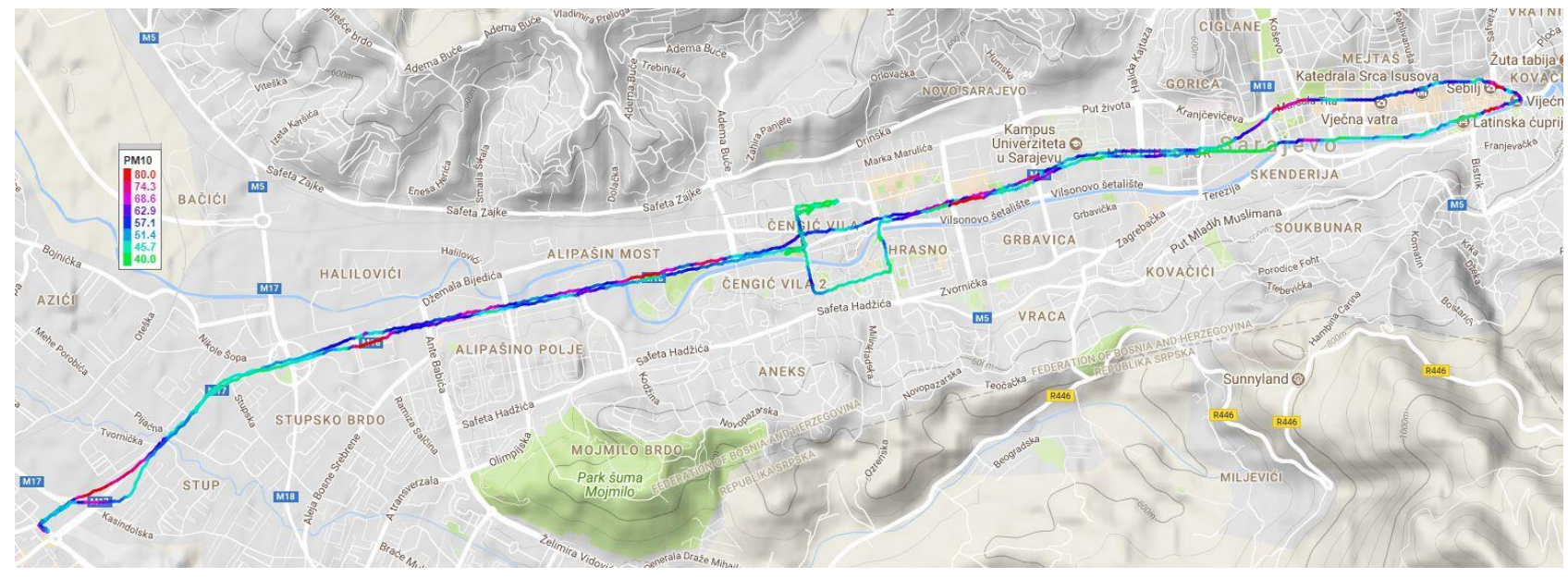

Fig. 2. Distribution of PM10 pollution over the main longitudinal road through the city

We can see red spots (increased PM10 pollution) in the Figure 2 on several road segments, but it is not clear from the figure if there is any specific reason for that. However, if we plot the combined graph of speed of the motorbike and PM10 concentration (Figure 3), we can notice an interesting correlation: whenever the speed of the motorbike drops to zero and keeps that value for certain amount of time, the corresponding PM10 concentrations are raising sharply! This happens on big intersections, where the traffic is slowed down, so there is increased air pollution from the vehicles' emission. In the left part of the Figure 2, we have the main interchange in the city (Stup interchange), and we can see that PM10 concentrations are below the average value from the graph, which looks surprising at first glance, taking into account high intensity of traffic on the interchange. Few years ago, that interchange was known for long traffic jams. However, the Stup interchange has been reconstructed recently. It is a modern and wide interchange now, and traffic jams are almost nonexistent. This is clear indicator of strong implications of urban planning to the air pollution levels, the PM10 in this case.

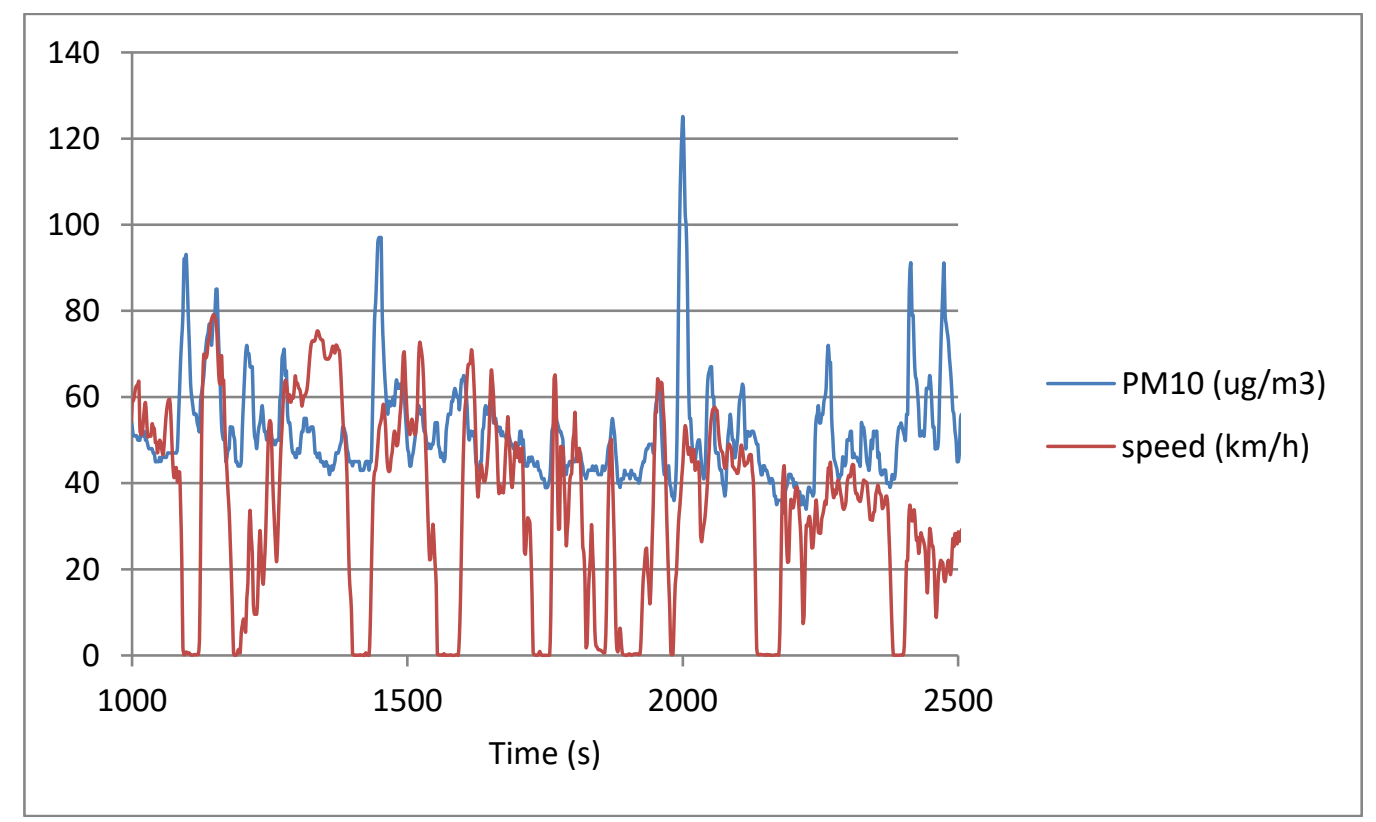

Fig. 3. Correlation between traffic speed and PM10 pollution 
Second test case is performed with the mPMOC mounted to the bicycle. The test track was different know, with segmenets where motor vehicles were not allowed during the test duration (Vilsonovo promenade). The track included both urban and suburban areas (Figure 4). We can clearly see from the Figure 4 that the air pollution with PM10 particles is much weaker in the area with limited traffic and lot of trees (Vilsonovo promenade) in comparison to walk paths near the major roads. Especially strong air pollution was recorded over (many) city hills (Koševsko brdo, Kobilja Glava, etc.) due to the strong emissions from vehicles driving over the aformentioned inclinations.

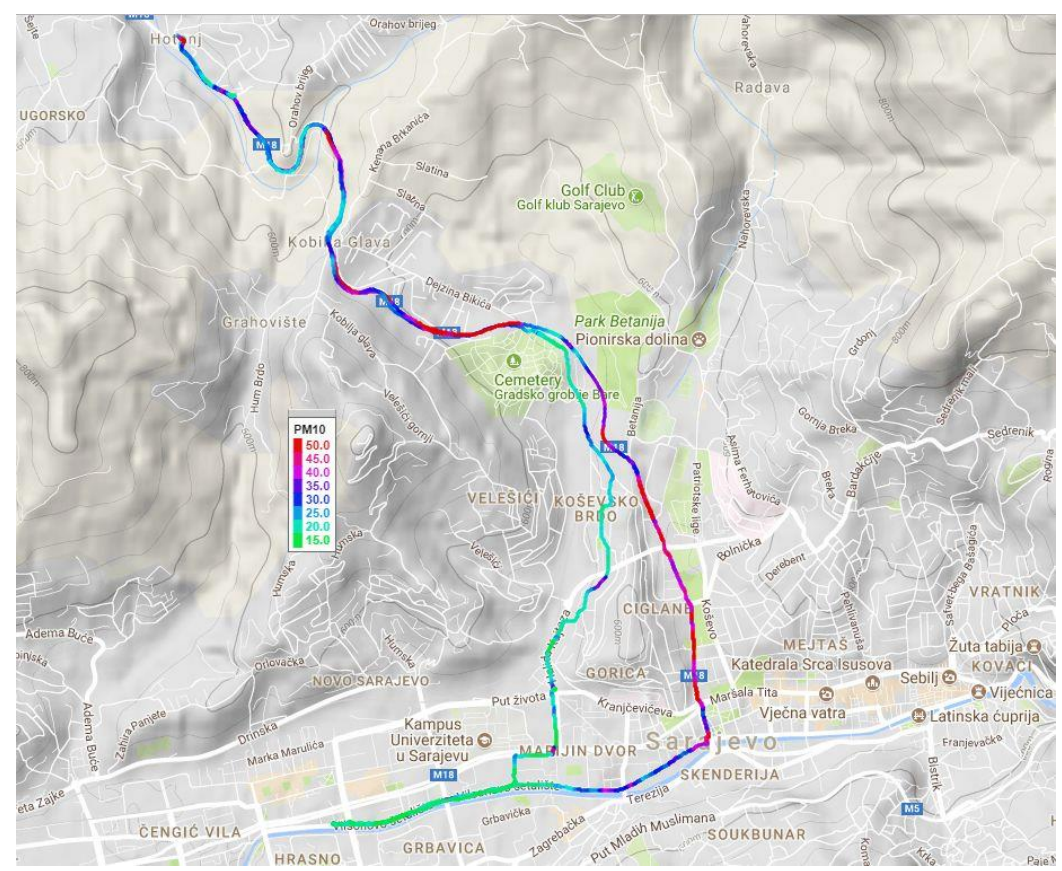

Fig. 4. PM10 pollution in urban and suburban section

Finally, the mPMOC was mounted to the in-house developed unmanned aerial vehicle (UAV) [3], to evaluate the possibility of measurements of vertical profiles of PM10 concentration. The test location was city quart Otoka, where the Governmental automatic station for measurements of air pollution is installed. Altitude of test location is about 500 meters, while the UAV lifted mPMOC approximately 700 meters above the city. The date of measurement was 19-032017 i.e. at the end of the winter. A very interesting vertical profile of PM10 concentration was observed (Figure 5): PM10 concentrations were initially decreasing with the altitude for several hundred meters, and then suddenly reversing the trend! The temperature profile indicates the interesting layer of temperature inversion some 300 meters above the city. This layer obstructed natural convection of the air, preventing the ventilation of major pollutants.

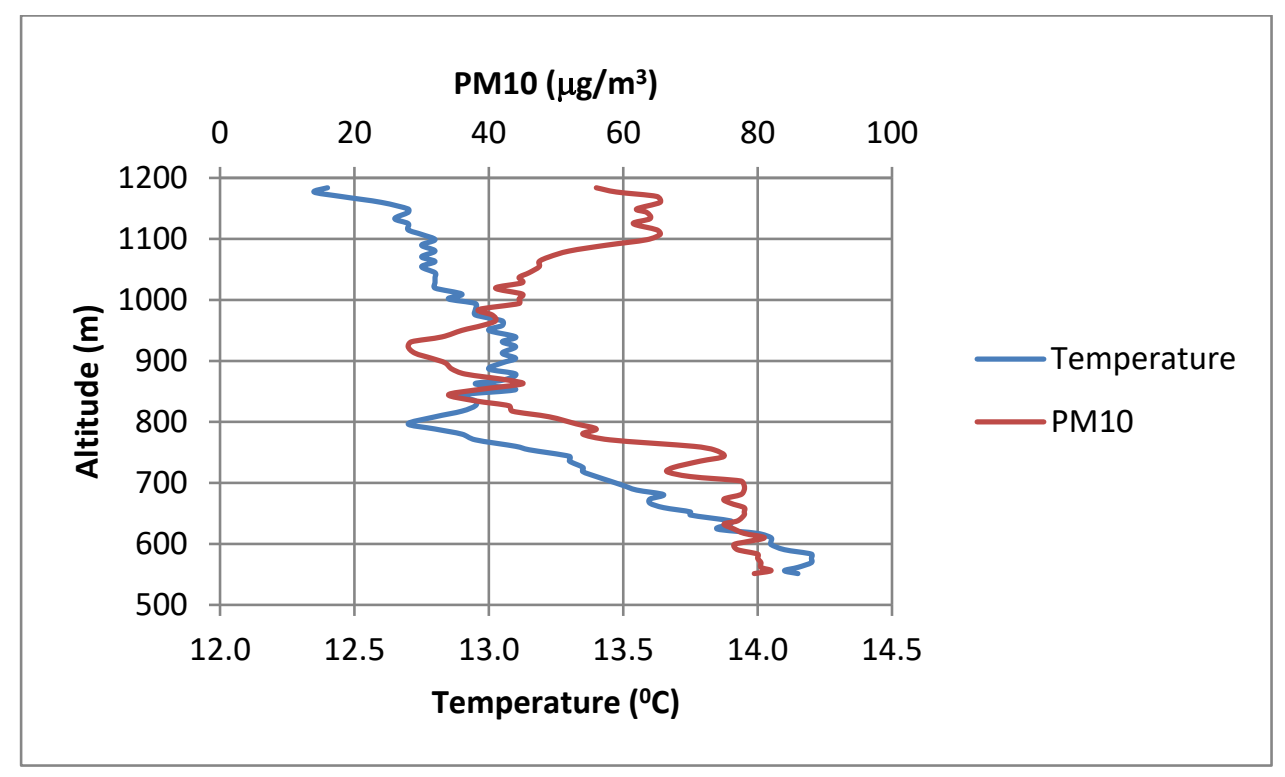

Fig. 5. Vertical profiles of temperature and PM10 concentration 


\section{Conclusion}

Major goal of present research is the evaluation of the possibility of using the mPMOC on various mobile platforms. The mPMOC was tested for mobile measurements of the particulate matter concentrations in the air using the following carriers: the motorbike, the bicycle and the unmanned aerial vehicle. In these three applications, the mPMOC surpassed all expectations: it produced meaningful results, it had good resolution and fast reaction time. The obtained results indicated interesting correlations, such as:

- horizontal distribution of PM concentrations vs. traffic intensity,

- horizontal distribution of PM concentrations vs. orography of the terrain,

- vertical distribution of PM concentrations vs. vertical temperature profile etc.

In comparison to the fixed monitoring stations operated by the Governmental institutions, the mPMOC demonstrated clear advantages, most important of all: low cost and high mobility. Does it make the fixed and expansive monitoring stations obsolete? Actually no, it doesn't. The proposed method is more like the extension to the public network of monitors, rather than the replacement for them. It tries to overcome major disadvantages of the fixed stations (high costs and low mobility). However, properly calibrated and maintained fixed stations offer superior reliability of the measured pollutants concentrations, since they are based on gravimetric methods. All optical counters used for measurements of the air pollution use certain assumptions. These assumptions are mentioned in the introduction of this paper, and can have significant influence on the accuracy of measurements (especially assumptions 1-3).

Thus, we propose careful approach when using optical counters. They should be used as the supplement to the other techniques, such as: gravimetric methods, source appointment studies, computer simulations (turbulence modeling and dispersion programs) etc.

For the future work, we propose combination of different methods and evaluation of the mPMOC performance under various scenarios, such as the strong air pollution during the winter (due to the temperature inversion). More $\mathrm{mPMOC}$ devices should be constructed and used for simultaneous measurements of PM concentrations across the city. The application of unmanned aerial vehicles looks very promising, more measurements under different conditions would be very welcome. Finally, concentrations of other air pollutants $\left(\mathrm{SO}_{2}, \mathrm{NO}_{\mathrm{x}}, \mathrm{CO}, \mathrm{O}_{3}\right)$ should be measured as well. In other to keep the key advantages of mPMOC (low-cost and high mobility), the only viable option for mentioned pollutants is to use electrochemical sensors for measurements of their concentrations. We will try to implement more sensors in the future, and test them together with the optical PM sensor.

\section{References}

[1] WHO Air quality guidelines for particulate matter, ozone, nitrogen dioxide and sulfur dioxide (2006). World Health Organisaton

[2] Andrejiova, M[iriam]; Kralikova, R[uzena] \& Wessely, E[mil] (2016). The Air Quality Assessment from the Stationary Source Air Pollution, Proceedings of the 26th DAAAM International Symposium, pp.0082-0088, B. Katalinic (Ed.), Published by DAAAM International, ISBN 978-3-902734-07-5, ISSN 1726-9679, Vienna, Austria DOI:10.2507/26th.daaam.proceedings.012

[3] Masic, A.; Musemic, R. \& Dzaferovic-Masic, E. (2016). Temperature Inversion Measurements in Sarajevo Valley Using Unmanned Aerial Vehicles, Proceedings of the 27th DAAAM International Symposium, pp.0423-0427, B. Katalinic (Ed.), Published by DAAAM International, ISBN 978-3-902734-08-2, ISSN 1726-9679, Vienna, Austria, DOI: $10.2507 / 27$ th.daaam.proceedings.062

[4] Largeron Y. \& Staquet C. (2016). Persistent inversion dynamics and wintertime PM10 air pollution in Alpine valleys. Atmospheric Environment, 135 (2016) 92-108, DOI: http://dx.doi.org/10.1016/j.atmosenv.2016.03.045

[5] Hergert W. \& Wriedt T. (2012). The Mie Theory. Springer, ISBN 978-3-642-28737-4, ISSN 0342-4111, DOI: https://doi.org/10.1007/978-3-642-28738-1, Berlin, Heidelberg

[6] ISO 13320:2009 (2009). Particle size analysis - Laser diffraction methods. International Organization for Standardization, Geneva, Switzerland.

[7] Masic, A. (2015). Unmanned Aerial Vehicle as Data Acquisition System. Journal of Trends in the Development of Machinery and Associated Technology. Vol. 19, No. 1, 2015, ISSN 2303-4009 (online), p.p. 181-184.

[8] http://www.aqmd.gov/docs/default-source/aq-spec/resources-page/plantower-pms5003-manual_v2-3.pdf, (2016). Accessed on: 2017-09-20

[9] http://www.gpsvisualizer.com, (2017). Accessed on: 2017-09-20 